\title{
(6) OPEN ACCESS Use of illicit tobacco following introduction of
standardised packaging of tobacco products in
Australia: results from a national cross-sectional survey
}

\author{
Michelle Scollo, Meghan Zacher, Kerri Coomber, Melanie Wakefield
}

Centre for Behavioural Research in Cancer, Cancer Council Victoria, Melbourne, Victoria, Australia

\section{Correspondence to} Dr Michelle Scollo, Centre for Behavioural Research in Cancer, Cancer Council Victoria, 615 St Kilda Rd, Melbourne, VIC 3004, Australia;

mscollo@cancervic.org.au

Received 29 September 2014 Accepted 13 January 2015

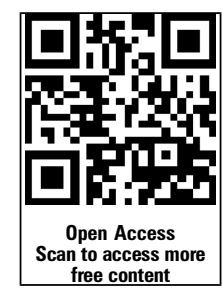

CrossMark

To cite: Scollo M,

Zacher $\mathrm{M}$, Coomber $\mathrm{K}$, et al. Tob Control 2015;24: ii76-ii81.

\author{
ABSTRACT \\ Objectives To assess whether following \\ standardisation of tobacco packaging in Australia, \\ smokers were, as predicted by the tobacco industry, \\ more likely to use illicit tobacco.
}

Methods National cross-sectional telephone surveys conducted continuously from April 2012 (6 months before implementation of plain packaging (PP)) to March 2014 (15 months after) using responses from current cigarette smokers $(n=8679)$. Changes between pre-PP, the transition to PP and PP phase were examined using logistic regression models.

Results Among those whose factory-made cigarettes were purchased in Australia, compared with pre-PP, there were no significant increases in the PP phase in use of: 'cheap whites' $(<0.1 \%$; OR $=0.24,95 \% \mathrm{Cl} 0.04$ to $1.56, p=0.134$ ); international brands purchased for $20 \%$ or more below the recommended retail price (0.2\%; OR=3.49, 95\% Cl 0.66 to $18.35, p=0.140)$; or packs purchased from informal sellers $(<0.1 \%$; $\mathrm{OR}=0.24,95 \% \mathrm{Cl} 0.04$ to $1.47, \mathrm{p}=0.124)$. The prevalence of any use of unbranded illicit tobacco remained at about $3 \%$ (adjusted OR=0.79, $95 \% \mathrm{Cl}$ 0.58 to $1.08, p=0.141$ ).

Conclusions While unable to quantify the total extent of use of illicit manufactured cigarettes, in this large national survey we found no evidence in Australia of increased use of two categories of manufactured cigarettes likely to be contraband, no increase in purchase from informal sellers and no increased use of unbranded illicit 'chop-chop' tobacco.

\section{INTRODUCTION}

Opponents of plain packaging (PP) in Australia claimed that the legislation would have major unintended consequences, ${ }^{1-3}$ in particular that the standardised appearance of the packs would make them easier to counterfeit ${ }^{4}$ and that this, combined with the reduced valuing of brands, would lead to an increase in use. The increased use of contraband cigarettes as well as unbranded illicit tobacco, it was argued, would disadvantage retailers and advantage 'criminal gangs' purported to be widely involved in its distribution. ${ }^{5}$ Many of the same arguments have been proffered by those opposed to the introduction of standardised packaging in the UK, ${ }^{78}$ Ireland ${ }^{9}$ and New Zealand. ${ }^{10} 11$

Studies funded by Australian tobacco companies, which rely heavily on surveys of discarded cigarette packs, have reported increases in the size of the illicit tobacco market following the introduction of PP legislation. ${ }^{12}{ }^{13}$ Packs discarded in public places are likely to provide a poor representation of the universe of all packs used by smokers. ${ }^{14-17}$ Further, such studies cannot determine the proportion of packs non-compliant with Australia's packaging legislation that were legitimately purchased overseas either duty-free or with duty paid on entry. ${ }^{16-18}$ While consumer surveys provide alternative estimates of use of illicit tobacco not subject to these problems, respondents may not know the tax-paid status of the tobacco products they purchase, may not admit to knowingly buying illicit tobacco or conversely may be more ready to believe than is warranted that cigarettes sold at low prices are counterfeit. However, directly observing smokers' packs ${ }^{19}$ or asking smokers objective concrete facts about their packs is likely to elicit responses that are both honest and less subject to respondent error.

In their study across 18 European countries, Joossens et $a l^{19}$ asked cigarette smokers to show field interviewers their latest purchased pack of cigarettes or hand-rolled tobacco. Packs were defined as illicit if they had at least one of the following tax evasion indicators: (1) it was bought from illicit sources, as reported by smokers, (2) it had an inappropriate tax stamp, (3) it had an inappropriate health warning or (4) its price was substantially below the known price in their market. Adaptation of such a study in Australia needed to take account of that fact that tax stamps are not required in Australia and that only very well-funded studies could include fieldworkers able to examine packs. While an audit of Australian retailers' willingness to sell illicit tobacco conducted over 2012 and 2013 found some clear instances of products without health warnings ${ }^{20}$ the price was somewhat volatile over this period with instances of retailers trying to run down supplies of fully branded tobacco products, and a few cases of retailers selling stock in the old packaging at reduced rates afterwards. ${ }^{20}$ Further, tobacco companies claimed that prices of tax-paid products would fall sharply as a result of PP. Price was therefore not a stable or reliable indicator of illicit status over the period immediately prior to and after the introduction of PP. ${ }^{20}$

The World Customs Organization has identified the problem of cigarettes produced by operators in one country being smuggled to the illicit market in other countries-so-called 'cheap whites'. ${ }^{21}$ Its 2102 annual report listed a number of 'brand' names of cigarettes falling into this category. The report also listed several major international brands that appeared frequently among cigarettes identified by customs officials and intercepted because it 
was believed that the required taxes had not been paid. Any reported purchase of 'cheap whites' in Australia would represent clear cases of use of illicit tobacco. International brands such as Marlboro, Dunbill and Benson o Hedges are regarded as premium products in Australia and are rarely discounted. ${ }^{22}$ Any instances of purchase of such products at highly discounted prices would also therefore be highly likely to be illicit.

A study our group conducted in the Australian state of Victoria between 2011 and 2013-1 year before and 1 year after the introduction of $\mathrm{PP}$-detected no changes among smokers in use of unbranded tobacco, and low levels of use in November 2013 of cigarettes deemed likely to be contraband. ${ }^{23}$ The current study aims to extend this analysis using a large national data set and including baseline estimates of prevalence of smokers reporting any use of several categories of cigarettes which are highly likely to be contraband. We aimed to assess the significance of changes since the period prior to PP in the percentage of current cigarette smokers whose current pack of cigarettes:

- Carried a 'brand' name corresponding with known 'cheap whites';

- Was a brand frequently observed in international interceptions of contraband tobacco and was purchased in Australia at a suspiciously cheap price;

- Was purchased from an informal seller.

We also aimed to assess any changes in the proportion of smokers

- Who had any self-reported recent use of illicit unbranded tobacco.

\section{METHODS}

\section{Design and participants}

We used data from national cross-sectional telephone surveys which were conducted continuously between 9 April 2012 and 30 March 2014, with about 100 respondents per week, described more fully in Wakefield et $\mathrm{ll}^{24}$ (this volume).

This study includes $n=8679$ adult smokers who reported smoking at least once per month. Overall, 55\% were males; slightly more than one-quarter (29\%) were aged 18-29 years, $46 \%$ were $30-49$ years, and $26 \%$ were $50-69$ years. Additionally, 39\% of smokers lived in low socioeconomic status (SES) areas (as determined by a postcode-based measure of relative social disadvantage), ${ }^{25} 42 \%$ in mid-SES and $18 \%$ in high-SES areas. About one in three had not completed high school (32\%), about half had completed high school and/or had some tertiary education (56\%), and $13 \%$ had completed tertiary or higher education. The sample was limited to eligible respondents for each of the various analyses.

\section{Measures}

All respondents were asked "Do you currently smoke factorymade cigarettes only, roll-your-own cigarettes only, both, or neither of these?" Those who smoked factory-made (FM) or roll-your-own (RYO) cigarettes were asked to provide the name of the brand of the last cigarette they smoked as well as the variant name, pack size and pack number (single pack, multibuy or carton).

\section{'Cheap whites'}

Among FM cigarettes, 'cheap whites' included brands listed as produced specifically for the illicit market in the World Customs Organization's Illicit Trade report $2012^{21}$ and in reports by the international consulting company KPMG LLP ${ }^{12} 26$ including Dunstan, Jin Ling, Manchester, Modern, Regal, Sunlite, Timeless Time, Win, YunYan and Zhongnanhai. We coded three additional brands (Nanjing, Su Yan and Zig Zag) as 'cheap whites', as no registered manufacturer could be located.

'International brands purchased at suspiciously low prices' FM brands named in World Customs reports ${ }^{21}$ as frequently smuggled included Benson \& Hedges, Brooks, Camel, Craven A, Dunhill, Furongwang, Golden Eagle, LM, Lucky Strike, Marlboro, Mild Seven, Philip Morris, Rothmans, Shuangxi and 555. We considered current packs of these brands suspicious where the pack contained 20 cigarettes (the standard international pack size, and the one most frequently smuggled) and where the reported price paid was $20 \%$ or more below the recommended retail price (RRP), as reported in the Australian Retail Tobacconist. ${ }^{27}$ Where cigarettes were purchased in cartons from large retail outlets, this cut-off point was relaxed slightly to accommodate prices just a few cents below the cut-off and to take account of typically lower average prices for carton sales. We also considered packs of 25 cigarettes suspicious if the reported price was $20 \%$ or more below the RRP of a pack of 20 cigarettes of that brand.

\section{Purchase from informal sellers}

Current smokers were also asked "Where did you get the cigarettes you are currently smoking?" Those who indicated that relatives or friends had purchased their cigarettes were further asked from where this person had purchased them. Responses coded as a 'purchase from an informal seller' were 'from someone selling independently and/or illegally (not at a store, shop or other mainstream establishment, but perhaps at local markets, delivery service, door-to-door, in a pub or just in the street)'.

\section{Unbranded illicit 'chop-chop' tobacco}

Use of unbranded illicit tobacco known in Australia as 'chopchop' could be reported in several ways throughout the survey. After the initial question inquiring about tobacco products used, smokers were asked whether they currently smoked any other form of tobacco and, if so, which types; some respondents mentioned unbranded tobacco here. Respondents could also volunteer 'unbranded tobacco' as their 'current brand', usual brand (the brand smoked more than any other) or as 'another brand' they frequently smoked. The few respondents who said they did not know the brand name or refused to give it were directly asked whether it was unbranded tobacco. Finally, all respondents who did not report the use of unbranded tobacco in another way were directly asked if, in the past month, they had bought loose unbranded tobacco or cigarettes ("bought loose unbranded tobacco in a plastic bag, that is also known as chopchop" or "bought unbranded or chop-chop tobacco that has already been rolled into cigarettes"). From these questions, we created a measure indicating whether respondents reported any use of unbranded tobacco.

\section{Analysis}

We included current smokers of cigarettes (FM, RYO or unbranded) in our sample $(\mathrm{n}=8679)$. Data were weighted to account for telephony status (landline or mobile phone), gender, age by education and state of residence. ${ }^{24}$ All analyses were conducted in Stata V.12.1, adjusting for the effects of sample weighting on parameter estimates and SEs. We undertook logistic regression analyses to assess changes in outcomes between pre-PP (April to September 2012, $\mathrm{n}=2193$ ), the transition phase (October and November 2012, $\mathrm{n}=765$ ) and the PP phase (December 2012-March 2014, $\mathrm{n}=5721$ ). We also tested whether there were linear changes (eg, gradual increases) over 
the months during the PP phase. In analyses of use of unbranded tobacco, we controlled for sex, age group, SES and education. In analyses to see whether prevalence of three categories of packs likely to be contraband changed over time, we excluded packs reported as purchased duty-free or from overseas. Owing to extremely low prevalence, these analyses did not adjust for covariates.

To exclude the possibility that the pattern of changes (or lack thereof) was attributable to the $12.5 \%$ excise/customs duty increase that was effective from 1 December 2013 rather than to PP, we conducted sensitivity testing excluding the months after the tax increase (December 2013 through March 2014).

\section{RESULTS}

\section{'Cheap whites'}

Across the entire survey period, under $0.5 \%$ (unadjusted) of brands of last FM cigarette smoked were classified as 'cheap whites', and prevalence did not change overall between the pre-PP and the PP phase (table 1). Over the months within PP, the prevalence of these brands declined significantly.

\section{'International brands purchased at suspiciously low prices'}

The prevalence of international brands of FM cigarettes purchased in Australia for 20\% or more below the RRP was low in all phases (under 0.5\%, unadjusted) and did not increase between pre-PP and PP, nor linearly during PP.

\section{Packs purchased from informal sellers}

The prevalence of having purchased one's current pack of FM cigarettes from an informal seller did increase over the months of PP, but overall the prevalence remained negligible and there

Table 1 Prevalence of use of three categories of cigarettes likely to be contraband among the most recently purchased pack of FM cigarettes purchased in Australia-percentages and results of logistic regression models

\begin{tabular}{|c|c|c|c|c|}
\hline \multirow[b]{2}{*}{ Time period } & \multicolumn{3}{|c|}{$\begin{array}{l}\text { Differences between PP phases } \\
\text { —unadjusted modelst‡ }\end{array}$} & \multirow{2}{*}{$\begin{array}{l}\text { Linear trend during } \\
\text { PP-unadjusted model } \\
\text { OR }\end{array}$} \\
\hline & Per cent & OR & $95 \% \mathrm{Cl}$ & \\
\hline \multicolumn{5}{|l|}{ 'Cheap whites' } \\
\hline Pre-PP & 0.2 & 1.00 & & \\
\hline Transition & 0.2 & 1.15 & 0.12 to 11.39 & \\
\hline PP & $<0.1$ & 0.24 & 0.04 to 1.56 & $0.92 *$ \\
\hline \multicolumn{5}{|c|}{ Suspiciously priced international brand } \\
\hline Pre-PP & $<0.1$ & 1.00 & & \\
\hline Transition & 0.1 & 1.80 & 0.16 to 20.85 & \\
\hline PP & 0.2 & 3.49 & 0.66 to 18.35 & 0.97 \\
\hline \multicolumn{5}{|c|}{ Purchased from informal seller§ } \\
\hline Pre-PP & 0.1 & 1.00 & & \\
\hline Transition & 0.2 & 1.83 & 0.19 to 17.84 & \\
\hline $\mathrm{PP}$ & $<0.1$ & 0.24 & 0.04 to 1.47 & $1.63^{*}$ \\
\hline \multicolumn{5}{|c|}{$\begin{array}{l}\text { * } p<0.05 \text {. } \\
\text { tOf } n=8679 \text { cigarette smokers, } n=6658 \text { said the last cigarette they smoked was a } \\
\text { brand of FM cigarettes. We excluded those who did not provide their brand name of } \\
\text { the last cigarette they smoked ( } n=193) \text {, or who reported a brand of e-cigarettes, } \\
\text { cigars or cigarillos ( } n=11) \text {, or who purchased their current pack duty-free or from } \\
\text { overseas ( } n=60) \text {. Analysed } n=6395 \text {. } \\
\text { ¥Models did not control for respondent characteristics due to low cell sizes. } \\
\text { §ln addition, those who did not provide a valid pack size }(n=126) \text { were not asked } \\
\text { where they purchased their cigarettes from and were excluded from the 'informal } \\
\text { seller' analyses; analysed } n=6268 \text {. } \\
\text { FM, factory-made; PP, plain packaging. }\end{array}$} \\
\hline
\end{tabular}

was no difference in odds from the pre-PP to the PP phase (table 1).

\section{Unbranded 'chop-chop' tobacco}

Table 2 shows the unadjusted and adjusted proportions of four categories of use of unbranded illicit tobacco and combined as 'any reported unbranded illicit tobacco use'. There was no change between the pre-PP and the latter two phases for regular, current or other unbranded tobacco use; the reported use in these three categories was less than $1 \%$ in all phases. The prevalence of purchasing unbranded tobacco in the past month declined significantly from the pre-PP to the PP phase. Lastly, any reported use of unbranded illicit tobacco was between 3\% and $4 \%$ in each phase and did not change significantly between the pre-PP and the PP phase or over the months of PP.

\section{Sensitivity testing}

Sensitivity tests excluding the months after the $12.5 \%$ increase in tobacco excise and customs duties in December 2013 (PP post-tax) produced a slightly different pattern of findings. The significant linear decrease in the prevalence of 'cheap whites' in the months of PP was no longer significant (unadjusted $\mathrm{OR}=1.01, \mathrm{p}=0.789$ ). No respondents at all purchased their pack of FM cigarettes from an informal seller in this restricted sample (December 2012-November 2013). The non-significant linear decline $(p=0.054)$ in current use of unbranded tobacco in the months during PP became significant when excluding the post-tax period (adjusted $\mathrm{OR}=0.87, \mathrm{p}=0.042$ ). The nonsignificant linear decline in use of illicit unbranded tobacco in the months during PP became significant when we excluded the post-tax period (adjusted $\mathrm{OR}=0.94, \mathrm{p}=0.042$ ). These results suggest that the use of all three forms of illicit tobacco declined after the introduction of PP, but that the use of contraband cigarettes and unbranded tobacco may have increased slightly after the 1 December 2013 increase in excise/customs duty.

\section{DISCUSSION}

The results of this large national study confirm those of our smaller state-based study conducted in Victoria which found no increase in use of unbranded illicit tobacco and low levels of use of cigarettes likely to be contraband. ${ }^{23}$ This study extends these findings by showing no increase in use, before versus after the introduction of PP, of two key subsets of cigarettes likely to be contraband-those that are so-called 'cheap whites' produced specifically for the illicit market, and those brands frequently identified in customs interceptions internationally and purchased by survey respondents for a suspiciously low price. We also found no increase in use of cigarettes purchased from informal sources. The prevalence of any level of use of unbranded tobacco did not change and purchasing unbranded tobacco in the past month declined following the implementation of PP.

This study used a considerably larger national sample and was also stronger than the Victorian one in that it asked respondents to report on the brand of cigarettes they were currently smoking rather than only asking respondents about their 'regular' brand and their 'usual' price and place of purchase. Respondent reporting of the brand they are currently smoking is likely to be less subject to error and approximation. Like the Victorian study, this survey recruited participants via random digit dialling to landline and mobile phones, and is more likely than landline-only or online surveys to be representative of smoking patterns in the Australian smoker population.

Our study has several limitations. It excluded those people who do not speak English-just over 2.6\% of the Australian 
Table 2 Prevalence of categories of unbranded illicit tobacco use among cigarette smokers—percentages and results of logistic regression model

\begin{tabular}{|c|c|c|c|c|c|c|c|}
\hline \multirow[b]{2}{*}{ Time period } & \multicolumn{3}{|c|}{$\begin{array}{l}\text { Differences between PP phases-unadjusted } \\
\text { modelst }\end{array}$} & \multicolumn{3}{|c|}{$\begin{array}{l}\text { Differences between PP phases—adjusted } \\
\text { modelst‡ }\end{array}$} & \multirow{2}{*}{$\begin{array}{l}\text { Linear trend during } \\
\text { PP_-adjusted models } \\
\text { OR }\end{array}$} \\
\hline & Per cent & OR & $95 \% \mathrm{Cl}$ & Per cent & OR & $95 \% \mathrm{Cl}$ & \\
\hline \multicolumn{8}{|c|}{ Regular unbranded use } \\
\hline Pre-PP & 0.1 & 1.00 & & 0.1 & 1.00 & & \\
\hline Transition & 0.4 & 2.50 & 0.43 to 14.58 & 0.4 & 2.45 & 0.44 to 13.63 & \\
\hline PP & 0.2 & 1.48 & 0.47 to 4.67 & 0.2 & 1.48 & 0.46 to 4.73 & 1.03 \\
\hline \multicolumn{8}{|c|}{ Current unbranded use } \\
\hline Pre-PP & 0.2 & 1.00 & & 0.2 & 1.00 & & \\
\hline Transition & 0.1 & 0.42 & 0.05 to 3.61 & 0.1 & 0.41 & 0.05 to 3.58 & \\
\hline PP & 0.4 & 2.42 & 0.90 to 6.54 & 0.4 & 2.40 & 0.89 to 6.50 & 0.90 \\
\hline \multicolumn{8}{|c|}{ Nominated as 'another type of tobacco smoked' (other unbranded use) } \\
\hline Pre-PP & 0.2 & 1.00 & & 0.2 & 1.00 & & \\
\hline Transition & 0.1 & 0.68 & 0.07 to 6.14 & 0.1 & 0.62 & 0.07 to 5.79 & \\
\hline PP & 0.3 & 1.43 & 0.44 to 4.63 & 0.3 & 1.37 & 0.42 to 4.45 & 0.94 \\
\hline \multicolumn{8}{|c|}{ Purchased unbranded tobacco in the past month } \\
\hline Pre-PP & 3.2 & 1.00 & & 3.2 & 1.00 & & \\
\hline Transition & 3.0 & 0.94 & 0.55 to 1.60 & 2.9 & 0.91 & 0.53 to 1.57 & \\
\hline PP & 2.1 & $0.64^{*}$ & 0.45 to 0.91 & 2.1 & $0.63^{*}$ & 0.44 to 0.90 & 0.97 \\
\hline \multicolumn{8}{|c|}{ Any unbranded tobacco use§ } \\
\hline Pre-PP & 3.7 & 1.00 & & 3.7 & 1.00 & & \\
\hline Transition & 3.5 & 0.96 & 0.59 to 1.57 & 3.5 & 0.93 & 0.57 to 1.53 & \\
\hline PP & 3.0 & 0.80 & 0.58 to 1.09 & 3.0 & 0.79 & 0.58 to 1.08 & 0.96 \\
\hline
\end{tabular}

population ${ }^{28}$ - so it may have slightly under-represented those recent immigrants who still prefer brands from their country of birth and who continue to buy these either on return visits or who receive them through the mail or by some other means. It did not include packs purchased over the internet or overseas, some of which may also have been beyond duty-free allowances and on which duty was not paid. However, as we have reported elsewhere, ${ }^{29}$ the numbers who purchased via these means remained very low throughout the survey-about $0.1 \%$ for internet purchases and $1.8 \%$ pre-PP declining to $0.6 \%$ during PP for purchases from overseas and duty-free. Another limitation results from exclusions resulting from the sequencing of questions in the survey. By excluding those who did not provide a brand name, we may have underestimated those who purchased from informal sources. Note, however, that the numbers are small and that this limitation applies equally to phases before and after introduction of PP.

Since we limited the analysis to categories of contraband cigarettes for which we could obtain reliable objective data, our study was unable to assess changes in use of any top-selling Australian cigarettes that had somehow got into the illicit market. Also since we were unable to apply stable price-based criteria to assess likely illicit status, we would have failed to detect cigarettes that have been counterfeited to appear like common Australian brands. Price-based criteria may need to be included in future studies attempting to quantify the use of illicit tobacco. However, at this time, this does not appear to be a consequential omission. Neither the Australian Customs and Border Protection Agency ${ }^{30}$ nor the industry-funded discarded pack studies ${ }^{12}{ }^{13}$ have so far identified counterfeited cigarettes as a significant problem. In fact, the latest industry-funded study by KPMG LLP states that to date in empty pack studies 'there has been no evidence of counterfeit plain packaging cigarettes' (ref. 13, p.40).

Some respondents may have been reluctant to report on the use of unbranded tobacco; however, there is no reason to believe any such reluctance would be more common after, compared with prior to, December 2012. Use of unbranded tobacco could be detected at multiple question points throughout the survey, so it is unlikely that the total estimates of prevalence have excluded any current or recent use. Survey items used to determine whether packs of FM cigarettes were likely to be contraband were objective and easy to understand, and in the context of the overall survey were unlikely to have been alarming to respondents.

While small retailers interviewed in industry-funded studies may have believed that rates of use of illicit tobacco have increased following PP implementation, ${ }^{31}$ we found no evidence of such increases. We also found much lower levels of use of illicit unbranded tobacco than those reported in less representative industry-funded internet surveys ${ }^{12} 2632$ where the sampling frame comprises people who opt in and earn incentives for survey participation. ${ }^{16}{ }^{17}$ While this study was unable to assess the absolute level of use of illicit tobacco, three important objective measures of use of contraband cigarettes did not increase following the introduction of PP, and there was no increase in use of unbranded tobacco. Results are in line with those reported in Australia's National Drug Strategy Household Survey which found fewer than $3.6 \%$ of smokers 
reporting any current use of illicit unbranded tobacco in 2013, significantly fewer than in 2010 or 2007 . Under $1 \%$ reported use of illicit unbranded tobacco 'half the time or more'. ${ }^{33}$ While various indicators of use of illicit tobacco should continue to be monitored through population surveys, retail audits and analysis of customs interceptions, our study suggests that industry estimates of the extent of use of illicit tobacco are exaggerated.

\section{What this paper adds}

\section{What is already known on this subject}

- The tobacco industry vigorously opposed the introduction of plain packaging in Australia and warned of an increase in use of illicit tobacco.

- Research conducted prior to and after the introduction of plain packaging found no evidence of an increase in the availability of illicit tobacco from a representative sample of small retail outlets and no evidence of increased use of unbranded tobacco among a representative sample of smokers.

\section{What this paper adds}

- In a larger national sample, this study found no evidence of increases in two important categories of contraband cigarettes and no increase in purchases from informal sellers. The reported use of illicit unbranded tobacco also did not increase.

\begin{abstract}
Acknowledgements Thank you to Dr Emily Brennan who provided several suggestions for analysis and to Ms Megan Bayly for data checking and review.
\end{abstract}

Contributors MS and MW designed this study. MZ cleaned the data files, undertook the analysis and reported the results. MS drafted the manuscript with contributions from all authors. KC undertook further analysis. All authors approved the final manuscript.

Funding The National Plain Packaging survey was funded under a contract with the Australian Government Department of Health and Ageing.

Competing interests The authors wish to advise that MS was a technical writer for and MW a member of the Tobacco Working Group of the Australian National Preventive Health Task Force and MW was a member of the Expert Advisory Committee on Plain Packaging that advised the Australian Department of Health on research pertaining to the plain packaging legislation. MW hold competitive grant funding from the Australian National Health and Medical Research Council and MW holds competitive grant funding from the US National Institutes of Health, Australian National Preventive Health Agency and BUPA Health Foundation.

Ethics approval The survey was approved by the Cancer Council Victoria Human Ethics Committee (HREC 0018).

Provenance and peer review Not commissioned; externally peer reviewed.

Open Access This is an Open Access article distributed in accordance with the Creative Commons Attribution Non Commercial (CC BY-NC 4.0) license, which permits others to distribute, remix, adapt, build upon this work non-commercially, and license their derivative works on different terms, provided the original work is properly cited and the use is non-commercial. See: http://creativecommons.org/ licenses/by-nc/4.0/

\section{REFERENCES}

1 British American Tobacco Australia. Submission on the Tobacco Plain Packaging Bill 2011. Canberra: Department of Health and Ageing Consultation website, 2011. http://content.webarchive.nla.gov.au/gov/wayback/20130904173432/http://www. yourhealth.gov.au/internet/yourhealth/publishing.nsf/Content/ 2EE2F6F3EC74F628CA2579540005F68B/\$File/British\%20American\%20Tobacco\% 20Australia\%20-\%20Public\%20Submission.pdf (accessed Oct 2014).

2 Philip Morris Limited. Commoditising tobacco products through plain packaging will harm public health, violate treaties and does not meet the test of 'evidence-based policy'. Melbourne, 2011. http://webarchive.nla.gov.au/gov/20130329051831/http:// www.yourhealth.gov.au/internet/yourhealth/publishing.nsf/Content/ Phillip-Morris-Limited Phillip-Morris-Limited-2 (accessed Oct 2014).
3 Imperial Tobacco Australia Limited. Submission to the Department of Health and Ageing regarding the Tobacco Plain Packaging Bill 2012 (exposure draft) and consultation paper. Sydney, 2011. http://webarchive.nla.gov.au/gov/

20130329044623/http://www.yourhealth.gov.au/internet/yourhealth/publishing.nsf/ Content/ppit ncr loe (accessed 10 Jan 2012).

4 Crowe D. Campaign questions expensive plain packaging experiment, May 17. 2011. http://www.bata.com.au/group/sites/bat_7wykg8.nsf/vwPagesWebLive/ D07WZEX6/\$FILE/medMD8GX5XH.pdf?openelement (accessed Jul 2014).

5 British American Tobacco Australia. Sydney number one hot spot for illegal tobacco. Sydney: BATA, 2011. http://www.bata.com.au/group/sites/BAT_7WYKG8.nsf/ vwPagesWebLive/D07WZEX6? opendocument\&SKN=1 (accessed May 2014).

6 British American Tobacco Australia. Booming illegal tobacco costs government billions. Sydney: BATA, 2013. http://www.bata.com.au/group/sites/BAT_7WYKG8. nsf/vwPagesWebLive/D09879X3?opendocument\&SKN=1 (accessed May 2014).

7 British American Tobacco (BAT). UK Standardised Packaging Consultation: Response of British American Tobacco UK Limited. 2012. http://www.bat.com/group/sites/ uk__3mnfen.nsf/vwPagesWebLive/D08WZC5E/\$FILE/medMD8WZC6J.pdf? openelement (accessed May 2014).

8 Japan Tobacco International (JTI). Response to the Department of Health's consultation on the standardised packaging of tobacco products. 2012. http://www. jti.com/how-we-do-business/key-regulatory-submissions/ (accessed May 2014).

9 Oireachtas Joint Committee on Health and Children. Public Health (Standardised Packaging of Tobacco) Bill presentations and submissions. Dublin: Houses of the Oireachtas, 2014. http://www.oireachtas.ie/parliament/oireachtasbusiness/committees_ list/health-and-children/submissionsandpresentations/ (accessed May 2014).

10 British American Tobacco (New Zealand) Ltd. Proposal to introduce plain packaging of tobacco products in New Zealand: submission by British American Tobacco (New Zealand) Limited. Wellington: Parliament of New Zealand, 2014. http://www. parliament.nz/en-nz/pb/sc/documents/evidence?Custom=00dbhoh_bill12969_ 1\&Criteria.PageNumber=2 (accessed May 2014).

11 Imperial Tobacco New Zealand Limited. Submission to Health Select Committe by Imperial Tobacco New Zealand Limited. Wellington: Parliament of New Zealand, 2014. http://www.parliament.nz/en-nz/pb/sc/documents/evidence? Custom=00dbhoh_bill12969_1\&Criteria.PageNumber=4 (accessed Sep 2014).

12 KPMG LLP. Illicit tobacco in Australia: 2013 full-year report. Sydney, 2014. http:/l www.bata.com.au/group/sites/BAT_7WYKG8.nsf/vwPagesWebLive/D09FC38M? opendocument\&SKN=1 (accessed Apr 2014).

13 KPMG LLP. Illicit tobacco in Australia: 2014 half year report. Sydney, 2014. http:/l www.bata.com.au/group/sites/BAT_7WYKG8.nsf/vwPagesWebLive/D09FC38M? opendocument\&SKN=1 (accessed 25 Nov 2014).

14 Ciecierski C. Working Paper-The Market for Legal and Illegal Cigarettes in Poland: A Closer Look at Demand and Supply-Side Characteristics. 2007. http://web.idrc.ca/ fr/ev-119595-201-1-DO_TOPIC.html (accessed Nov 2013).

15 Stoklosa M, Ross H. Contrasting academic and tobacco industry estimates of illicit cigarette trade: evidence from Warsaw, Poland. Tob Control 2014;23:e30-4.

16 Quit Victoria. Critique of, illicit tobacco in Australia: full year report 2013 by KPMG LLP. Melbourne, Australia: Cancer Council Victoria, 2014. http://www.cancervic.org. au/plainfacts/browse.asp?ContainerlD=illicittobacco (accessed Aug 2014).

17 Quit Victoria. Critique of, illicit tobacco in Australia: half year report 2014 by KPMG LLP. Melbourne, Australia: Cancer Council Victoria, 2014. http://www.cancervic.org. au/plainfacts/browse.asp?ContainerlD=illicittobacco (accessed Nov 2014).

18 Gilmore AB, Rowell A, Gallus S, et al. Towards a greater understanding of the illicit tobacco trade in Europe: a review of the PMI funded 'Project Star' report. Tob Control 2014;23:e51-61.

19 Joossens L, Lugo A, La Vecchia C, et al. Illicit cigarettes and hand-rolled tobacco in 18 European countries: a cross-sectional survey. Tob Control 2014;23:e17-23.

20 Scollo M, Bayly M, Wakefield M. Availability of illicit tobacco in small retail outlets before and after the implementation of Australian plain packaging legislation. Tob Contro/ Published Online First: 10 Apr 2014 doi:10.1136/tobaccocontrol-2013-051353

21 World Customs Organization. Illicit trade report, 2012. Brussels: WCO, 2013. http:/l www.wcoomd.org/en/media/newsroom/2013/june/wco-publishes-its-first-illicit-tradereport.aspx (accessed Jul 2013).

22 Scollo M, Bayly M. Section 13.3 The price of tobacco products in Australia in Chapter 13. The pricing and taxation of tobacco products in Australia (December 2014 update). Melbourne, Australia: Cancer Council Victoria, 2014. http://www. tobaccoinaustralia.org.au/chapter-13-taxation/13-3-the-price-of-tobacco-productsinaustralia (accessed Nov 2014).

23 Scollo M, Zacher M, Durkin S, et al. Early evidence about the predicted unintended consequences of standardised packaging of tobacco products in Australia: a cross-sectional study of the place of purchase, regular brands and use of illicit tobacco. BMJ Open 2014;4:e005873.

24 Wakefield M, Coomber K, Zacher M, et al. Australian adult smokers' responses to plain packaging with larger graphic health warnings 1 year after implementation: results from a national cross-sectional tracking survey. Tob Control 2015;24:ii17-25.

25 Australian Bureau of Statistics. Technical paper: socio-economic indexes for areas (SEIFA) 2011. Canberra, Australian Capital Territory: ABS, 2013. http://www.abs. gov.au/websitedbs/censushome.nsf/home/seifa2011 ?opendocument\&navpos=260 (accessed Apr 2014). 
26 KPMG LLP. Illicit tobacco in Australia: 2013 half year report. Sydney: 2013. http:/l www.bata.com.au/group/sites/BAT_7WYKG8.nsf/vwPagesWebLive/D09879X3? opendocument\&SKN=1 (accessed Nov 2013).

27 NSW Retail Tobacco Traders' Association. Price lists-cigarettes. Aust Retail Tobacconist 2013;87:1-2.

28 Australian Bureau of Statistics. 2071.0—Reflecting a Nation: Stories from the 2011 Census, 2012-2013. 2013. http://www.abs.gov.au/ausstats/abs@.nsf/Lookup/2071. Omain+features902012-2013 (accessed Jul 2014).

29 Scollo M, Zacher M, Coomber K, et al. Did consumers shift from small mixed businesses to discount outlets following the introduction of plain packaging in Australia? A national cross-sectional survey. Tob Control 2015;24:ii98-9.

30 Australian Customs and Border Protection Service. Annual report 2013-14. Canberra: ACBPS, 2014. http://www.customs.gov.au/site/page4283.asp
31 Roy Morgan Research. Impact of plain packaging on small retailers-wave 2. Melbourne: Australian Association of Convenience Stores, 2013. http://www.aacs. org.au/wp-content/uploads/2013/10/Impact-of-Plain-Packaging-on-Small-RetailersW2-Final-Report.pdf (accessed May 2014).

32 Deloitte. Illicit trade of tobacco in Australia: update for 2012: a report prepared for British American Tobacco Australia Limited, Philip Morris Limited and Imperial Tobacco Australia Limited. Sydney: British American Tobacco Australia, 2012. http://www.bata.com.au/group/sites/BAT 7WYKG8.nsf/ vwPagesWebLive/D09879X3?opendocument\&SKN=1 (accessed Aug 2014).

33 Australian Institute of Health and Welfare. National Drug Strategy Household Survey detailed report: 2013-supplementary tables. Canberra: AlHW, 2014. http://www.aihw.gov.au/publication-detail/?id=60129549469\&tab=3 (accessed Nov 2014). 